\title{
Formation of physical training of future engineers of the construction industry by means of programmed learning
}

\author{
Vladimir Kalmanovich*1[0000-0001-7637-4496], Alexey Kurshev², and Sergey Sevodin ${ }^{3}$ \\ ${ }^{1}$ Kazan State University of Architecture and Engineering, 420043 Kazan, Russia \\ ${ }^{2}$ Kazan National Research Technological University, 420111 Kazan, Russia \\ ${ }^{3}$ Kazan State Power Engineering University, 420034 Kazan, Russia
}

\begin{abstract}
Modern industrial activities connected with professional actions in limited space, in personal protective equipment, in various environmental conditions, with increased smoke, gas, radio emissions, etc., require great physical strength, agility and endurance. Under these conditions arises an objective necessity of scientific substantiation of the content and structure of the model of the students' physical training formation, providing their fullfledged preparation for modern professional activity. Materials and methods. We applied analysis of scientific and methodical literature, statistical methods, and expert evaluation method. There were used data from open sources on the problem of research and official statistics data. It is obvious that the model of physical training formation of construction university students developed by us is the most effective in improving the cognitive activity of the students. The success of realization of our hypothesis in this part is provided in active and exploratory learning schemes. Also, in the active and exploratory schemes of learning students actively develop skills, i.e., the ability to adapt the acquired skills to changing conditions. The dogmatic and passive schemes ensure effective formation of physical skills, namely, stable, clearly algorithmized structures of motor actions.
\end{abstract}

Keywords. Physical training formation, programmed learning, structural model.

\section{Introduction}

The transformations taking place in modern production not only significantly change its structure, but also significantly increase the importance of each graduated specialist. The created high-tech, mobile, multifunctional means of production, in order to solve the most complex tasks set before them, require special attention to the level of development of future specialists' physical training, the state of their personal physical preparedness $[1,2]$. At the same time, one of the key conditions providing efficiency and productivity of modern specialist's work is the availability of high general performance, which is based on good health and physical training. Today, a person's aspiration to improve and preserve his/her health is, first of all, his/her physical, mental and social well-being [3-6].

*Corresponding author: volek71@yandex.ru 
It is obvious that the problem of personal physical training development is also significantly actualized due to the requirements imposed on university graduates under the conditions of changing production tasks. Modern professional activity is characterized by high mental and physical strain of work, increased responsibility of a specialist $[7,8]$.

As shown in many studies, among the most important parameters determining the successful adaptation and social mobility of the individual are stress resistance, selfmanagement of mental and physical state, general efficiency and physical training of the person [9-13]. A person's health state depends on many factors, among which lifestyle is of great importance. The main components of lifestyle include: nutrition, lifestyle, organization of learning time, work and rest, attitude towards bad habits [14-16]. Production experience shows that qualitative performance of various types of professional activity by graduates of technical universities today is associated with significant physical and psychophysiological loads [17-19]. Modern production activities associated with professional actions in limited spaces, in personal protective equipment, in various environmental conditions, with increased smoke, gas pollution, radio emissions, etc., require great physical strength, dexterity and endurance $[20,21]$. At the same time, there are increasing trends in the number of graduates of technical universities with inadequate physical training, with bad habits, with the lack of need for sport activities as such. Under these conditions, there is an objective need for scientific substantiation of the content and structure of the model of students' physical training formation, which ensures their full-fledged preparation for modern professional activities [22-24].

\section{Materials and methods}

\subsection{Research methods and organization}

We used the analysis of scientific and methodical literature, statistical methods, and expert evaluation method. We used data from open sources on the problem of research and official statistics data.

\section{Results and discussion}

\subsection{Results of the study and their discussion}

In search of an answer to the emerging contradictions, we have attempted to analyze and systematize pedagogical models of physical education of students.

The analysis of the essence of emergence and diversity of physical training manifestations (L. Kuhn, N.I. Ponomarev, etc.) allowed us to assume that the real variety of pedagogical models in physical education is set by their anthropological and ontological components, namely by this or that combination of two interrelated and interdependent blocks: «body spirit» and «nature - culture». This provision allowed us to distinguish two main pedagogical models of physical education: body-oriented and socially-oriented.

The body-oriented model of physical education corresponds to the so-called concept of biologization in personality development (Hamilton, Krechmer, Sheldon, etc.), according to which a person is born with a certain set of qualities that somehow manifest themselves in the process of his/her biosocial development, and the task of training and education is to «follow human nature».

The purpose of body-oriented model of physical education of students is health promotion, achievement of normal physical development and general physical training in accordance with his natural (body-motor) abilities. 
In the implementation of body-oriented model of physical education of students the leading principles are nature-appropriate content, selective differentiation of the process and optimization of the interaction of subjects of educational and training process.

The criteria of body-oriented model of physical education of future specialists are the following: optimal health status, normal physical development, physical and healthpromotional knowledge, abilities, and skills.

The socially-oriented model of physical education is based on the sociological direction in theories of personality development (social learning theory - I.L. Pavlov, B.F. Skinner, etc.), according to which the main influence on personality formation, regardless of natural human inclinations, is provided by organized educational influences. In its essence this model is similar to the sociocentric model of pedagogical activity described by L.A. Belyaeva and I.G. Fomicheva.

The goals of socially-oriented physical education is determined based on the needs of the profession, while the graduate is considered as a means of achieving socially significant goals. The educational process within this model takes the form of general and special (professional-applied) physical training of a person, ensuring his/her socialization.

The main principles in the implementation of this pedagogical model in practice are as follows: unification of the content, intensification of the process and directivity of interaction between the subjects of the educational and pedagogical process.

The criteria of socially-oriented model of physical education, according to the unified educational programs, are knowledge, abilities, skills and physical training of a student.

A characteristic feature of the socially-oriented model of physical education is a clearly defined and diagnosed goal, as well as the presence of a rigid logic of progression of students in their development, which guidelines are standards, norms, and instructions.

The specified model is advisable to apply in educational institutions, when solving specific tasks of general and special (professional-applied) physical training, especially for work in extreme conditions (preferably, based on the voluntary choice of persons with a wellestablished system of life values).

Programmed learning (PL) emerged in the $1950^{\mathrm{s}}$, when the scientific and technological revolution (STR) demanded mass training of specialists in new professions in the shortest possible time. Rapid obsolescence and frequent change of professions, higher requirements for the level and quality of specialists' training resulted in the necessity to search for new effective training methods. On the other hand, the STR itself created a new basis for the improvement of learning technologies, which made it possible to provide the learning process with technical training aids and thereby dramatically increase its efficiency and quality.

However, there are few works devoted to the issue of using software in the formation of physical skills and abilities. The analysis of practice shows that often, instead of developing the training method itself, the authors limit themselves to the development of various programs and algorithmic instructions. The subject matter of software research is mostly limited to the «gymnastics» section. It seems particularly important for us to consider the possibilities of software as one of the means of increasing the efficiency of physical skills formation at all stages of training and various forms of physical education.

Teaching methodology should imply the delivery of the material in small portions (steps) containing the main points of pedagogical actions and being the basis for formation of systemic knowledge. Reduced doses of learning information allow students to independently operate with this amount of material, facilitate management of the learning process and, if necessary, allow multiple repetition of the task. All this is in line with the principles of programmed learning, which is based on the division of learning material into doses and its step-by-step learning. 
According to activity theory (A.N. Leontiev) and the modern representation of motor skill formation using microstructural analysis (N.A. Bernstein), the psychological structure of any motor skill is established. It consists of three blocks:

1. The block of formation of motor instructions or building an action program.

2. The block of action program implementation.

3. The block of control and correction.

This structure is universal. It is inherent in elementary and simple actions performed under relatively constant conditions, and complex actions under continuously changing conditions.

Organization of programmed microlearning (PML) allows achieving a high density of physical activity in the class. After the demonstration of the next activity, the instructor organizes a training session using effective methods of working with the trainees, combining individual training with mass coverage. This is achieved by dividing the students into groups of 2-5 people. In this case, the lesson is divided into a series of micro-lessons, each of which is really a micro-lesson both in terms of duration (2-10 minutes) and the number of students (2-5 people).

A microlearning lesson represents, on the one hand, as if a cell, a quantum of programmed learning, distinguished by the fact that its further division is impossible without violating the principles of programmed learning; on the other hand, a micro-lesson is a quantum of information, a minimal exercise for forming and improving physical skills and abilities, further reduction of which is impossible without harming the logical content of the learning material. This criterion of substantiality determines the minimal size of the programmed learning step and micro-lesson. During the work we investigated different models of microlessons at all stages of physical training teaching.

Microlearning acts as a way of joint actions of a teacher and students, leading students from ignorance to knowledge, from inability to ability, i.e., as a learning method. At the same time, programmed microlearning determines the composition and grouping of students, the structure of the lesson, the place and duration of the lesson, and the specifics of the activity. That is, it also expresses the organizational side of learning and acts as a new effective form of student training. This reveals an inseparable dialectical connection between the two most important categories of the learning process. We used programmed microlearning in the development of the methodology of stage-by-stage formation of physical skills and abilities.

When exploring the potential of programmed learning, it should be seen not just as a set of individual techniques and not just as a new teaching method, but as a holistic system with different tools, methods, and forms in its arsenal. Being one of the ways to improve the learning process, programmed learning implies the organization of science-based pedagogical process, corresponding to the current and future requirements of science and technology. It allows the management of the learning process itself on the basis of the principles of scientific organization of work.

Programmed learning, if it is understood literally, is learning by the program, when not only the material is programmed, but also the way it is learned, when the actions of both the student and the teacher are programmed. Programmed learning ensures guaranteed learning in the shortest possible time and at the lowest possible cost.

Recall the principles of programmed learning:

1. Dividing the material to be studied into portions.

2. Management of the learning process, operational control.

3. Providing reliable feedback.

4. Use of teaching training aids and visual aids.

5. The use of effective methods of organizing students.

The underlying principles of the software are the division of learning material into portions (doses), steps, frames and operational control. The basic structural unit of the software is an information element. In turn, each information item is divided into steps and each step into frames. 
It is particularly important to determine the magnitude of the information element. This is necessary to be able to plan the amount of material to be studied in the classroom and the tasks for independent work. It is also related to the development of information support by means of technical equipment and visual aids, organization of control and evaluation.

Naturally, at the initial stage of learning, the magnitude of the information element will be small and correspond to the amount of material needed to form one elementary skill. Then, as learning progresses and the physical skills formed become more complex, the information elements will enlarge and the amount of material that used to be an element of information, at the new stage, will represent only a step or even a frame of a step.

To learn how to program the learning process, it is necessary to reveal its functional structure. First of all, it is necessary to determine the composition of cognitive activity of students, and then on its basis the composition of cognitive influences. This requires a detailed description of the activity in the form of some model.

According to the theory of stage-by-stage formation of mental actions, programmed learning schemes should gradually increase in complexity. It is advisable to have the following types of programs (Ball G.A., Taranov J.H.).

\subsection{The $1^{\text {st }}$ scheme is dogmati}

Information about the actions required of the trainee is given without justification and without explanation. Training under this scheme includes: description (name) of the required actions, their demonstration, requirement from the trainees to repeat the shown actions. The students are only required to copy the actions (orientation framework of type 1). Accordingly, the control consists in determining the ability of students to repeat the required actions.

\subsection{The $2^{\text {nd }}$ programmed learning scheme is passive}

Information about the required actions is given with their justification and explanation. This scheme includes, accordingly, the formation of the idea of actions, their justification, practical demonstration and performance by students, control of the results of performance.

\subsection{The $3^{\text {rd }}$ programmed learning scheme is active}

Information about the actions required from students is presented with their justification and correction of actions in the given parameters. The material is presented in the dynamics of development of actions required from students. This scheme of programmed learning is called the basis of the active learning method, while the actions of students are referred as adaptation with uncoordinated stages of action.

\subsection{The $4^{\text {th }}$ programmed learning scheme is exploratory}

The delivery of information about the required results of an action is given without directly specifying the ways to achieve them. The structure of the steps included in such a programmed learning scheme is called the foundation of the exploratory learning method. For example, when performing an exercise training task, the student must identify the main elements of the exercise himself, select exercises to learn, prepare exercises to study the difficult elements, develop the sequence of his actions. 


\section{Conclusion}

Comparing these four schemes of programmed learning, it is obvious that the model of physical training formation of students of engineering university developed by us is the most effective in improving cognitive activity of students. The success of realization of our hypothesis in this part is provided in active and exploratory schemes of training. Also, in active and exploratory schemes of training students actively develop skills, i.e. abilities to adapt the received skills to changing conditions.

And the dogmatic and passive schemes ensure effective formation of physical skills, namely, stable, clearly algorithmized structures of motor actions.

\section{References}

1. F.R. Zotova. To a question about modern sports development trends, Theory and practice of physical education 2, 39-42 (2001).

2. V.L. Kalmanovich. Positive dynamics of the development of the Russian student sports union and student sports movement in the Russian Federation, Prospects for the development of modern student sports. Results of performances of Russian athletes at the Universiade 2013 in Kazan: Materials of the All-Russian Scientific and Practical Conference. FROM, 14-15 (2013).

3. J. Forster, K. Nigel, Li Pope, John Forster. The Political Economy of Global Sporting Organisations. - London: Routledge, (2004).

4. A. Guttmann. The Olympics: A history of the Modern Games. - Chicago: University of Illinois Press, (2002).

5. H. Jefferson Lenskyj. Inside the Olimpic Industry: Power, Politics and Activism. - New York: SUNY Press, (2000).

6. F. Lanary. One Hundred Years, The idea, the presidents, the achievements, The presidencies of Lord Killanin and Juan Antonio Samaranch 3, Fernand Landry, Madeleine Yerles. - Lausanne: CIO, (1996).

7. John R. Gold, Margaret M. Gold. Olympic Cities: Urban planning, city agendas and the world's Games, 1896 to the presen. London: Routledge, (2006).

8. John Bale, Mette Krogh-Christensen. Post-Olympism? Questioning Sport in the Twentyfirst Century. - Oxford: Berg, (2004).

9. L.A. Brown, M. Cresciani. Adaptable design in Olympic construction, International Journal of Building Pathology and Adaptation 35 (4), 397-416 (2017).

10. W. Wilson. Sports infrastructure, legacy and the paradox of the 1984 olympic games, International Journal of the History of Sport 32 (1), 144-156 (2015).

11. J. Thiel, G. Grabher. Crossing Boundaries: Exploring the London Olympics 2012 as a Field-Configuring Event, Industry and Innovation 22 (3), 229-249 (2015).

12. J.W. Lee. A winter sport mega-event and its aftermath: A critical review of post-Olympic Pyeong Chang, Local Economy 34 (7), 745-752 (2019).

13. Z. Sun. A brief analysis of sports venues in colleges and universities, Asian Social Science 11 (16), 114-117 (2015).

14. L.A. Brown, M. Cresciani. Adaptable design in Olympic construction, International Journal of Building Pathology and Adaptation 35 (4), 397-416 (2017).

15. W. Wilson. Sports infrastructure, legacy and the paradox of the 1984 olympic games, International Journal of the History of Sport 32 (1), 144-156 (2015).

16. J. Thiel, G. Grabher. Crossing Boundaries: Exploring the London Olympics 2012 as a Field-Configuring Event, Industry and Innovation 22 (3), 229-249 (2015).

17. J.W. Lee. A winter sport mega-event and its aftermath: A critical review of post-Olympic Pyeong Chang, Local Economy 34 (7), 745-752 (2019). 
18. Z. Sun. A brief analysis of sports venues in colleges and universities, Asian Social Science 11 (16), 114-117 (2015).

19. A.A. Bolotnikov, R.Sh. Garifullin, V.L. Kalmanovich, E.R. Mugattarova, R.R. Khairullin. Development of health-saving environment at engineering university, IOP Conference Series: Materials Science and Engineering 890, 012172 (2020). DOI: 10.1088/1757899X/890/1/012172.

20. E. Yakimova, P. Terehov, O. Salnikova, N. Ishmuhametova. Crowdsourcing as an approach to solving environmental problems by future construction engineers, IOP Conference Series: Materials Science and Engineering 890 (1), (2020). DOI: 10.1088/ 1757-899X/890/1/012174.

21. V.Y. Lebedinsky, O.I. Kuzmina, M.D. Kudryavtsev, V.I. Gruzenkin, T.G. Arutunian. Health monitoring of students of the III functional group for controlling and designing educational environment (physical education) in a non-sport university, Human Sport Medicine 19 (4), 78-91 (2019). DOI: 10.14529/hsm190410.

22. A.I. Kartavtseva, S.L. Sadyrin, E.A. Dergach, N.A. Bryukhanova. The use of electronic courses in the implementation of educational programs "Physical education and sport», «Applied physical education and sport» for students of the special educational department, Journal of Siberian Federal University - Humanities and Social Sciences 14 (2), 180-192 (2021). DOI: 10.17516/1997-1370-0710.

23. A.P. Anishenko, A.N. Arkhangelskaia, V.A. Zaborova, M.Y. Karganov, I.B. Alchinova, M.V. Polyakova, K.G. Gurevich. Three-year dynamics of the changes in the physical fitness, anthropometric development, food preferences, and metabolic changes in the students trained according to the modified methodology of physical culture, Voprosy Kurortologii, Fizioterapii, i Lechebnoi Fizicheskoi Kultury 95 (4), 31-40 (2018). DOI: 10.17116/kurort20189504131.

24. N.A. Fudin, A.A. Khadartsev, S.V. Moskvin. Transcranial electrostimulation and serotonin laser phoresis in the athletes experiencing a combined effect of fatigue and psycho-emotional stress, Voprosy Kurortologii, Fizioterapii, i Lechebnoi Fizicheskoi Kultury 96 (1), 37-42 (2019). DOI: 10.17116/kurort20199601137. 